The devil is in the detail: Deception and consistency over repeated interviews

Charlotte A. Hudson, Aldert Vrij, Lucy Akehurst \& Lorraine Hope

Department of Psychology, University of Portsmouth, UK

Word Count: 8, 207

Author Note:

Charlotte A. Hudson, Aldert Vrij, Lucy Akehurst, Lorraine Hope, Department of Psychology, University of Portsmouth, UK.

Correspondence concerning this article should be addressed to Charlotte A. Hudson, Department of Psychology, King Henry Building, King Henry I Street, Portsmouth, Hampshire, United Kingdom, PO1 2DY. Email: charlotte.hudson@port.ac.uk 


\begin{abstract}
Word count: 200

Research indicates that truthful statements typically contain more details than fabricated statements, and that truth tellers are no more consistent than liars over multiple interviews. In this experiment, we examine the impact of (i) multiple interviewers and (ii) reverse order recall on liars' and truth tellers' consistency and amount of reported detail over repeated recall attempts. Participants either took part in a mock crime (lying condition) or an innocent event (truth telling condition) which they were subsequently interviewed about in two separate interview phases. Truth tellers provided more details overall, and more reminiscent details than liars. There were no differences between veracity groups for the number of omissions made or repetitions reported. Despite the popular belief that inconsistency is a cue to deception, we found little support for the notion that consistency (or lack of consistency) offers a diagnostic cue to deception. We found little evidence that switching interviewer or recalling in reverse order induced inconsistencies in liars. In fact, due to the number of reminiscent details in truth tellers' accounts, our findings suggest that accounts provided by liars tend to be slightly more consistent than those provided by truth tellers. The materials for this paper can be found at osf.io/hgvmk/.
\end{abstract}

Keywords (5): consistency, detecting deception, investigative interviewing, lying, reverse order recall 


\section{The devil is in the detail: Deception and consistency over repeated interviews.}

Research has consistently shown that people are relatively poor at recognising when someone is lying (Hartwig et al., 2011; ten Brinke, Vohs, \& Carney, 2016). Meta-analyses reveal that humans' ability to detect deception rarely exceeds chance (Bond \& DePaulo, 2006), and that there is little difference in accuracy between laypeople and practitioners who work in fields where attempts to deceive are commonplace (Aamodt \& Custer 2006; Bond \& DePaulo, 2006). Even when investigators are trained to look for cues to deception, only a small to medium training effect for accuracy in distinguishing between truth tellers and liars is found with the largest effect sizes found for training that focuses on verbal content (Hauch, Sporer, Michael, \& Meissner, 2016).

Given people's poor ability to differentiate between truth tellers and liars, researchers have been working towards developing interviewing techniques designed to increase the differences in verbal cues between truth tellers and liars (e.g. Strategic Use of Evidence, SUE; Granhag \& Hartwig, 2015) and cognitive lie detection (Vrij, Leal, Mann, Vernham, \& Brankeart, 2015; Vrij, Fisher, \& Blank, 2017). In the current experiment, we examined the effect of two interviewing strategies (requests for reverse order reporting and changing the interviewer midway through an interview) on truth tellers' and liars' reports over two phases of an interview (i.e. two questioning periods with a short break in between), with respect to the amount of detail provided, and the consistency between the two recall attempts.

\section{Veracity: Detail and (in)consistency}

Truth tellers tend to provide more details in their accounts than liars (Amado, Arce, \& Fariña, 2015; Vrij, 2008; Vrij, Mann, Jundi, Hillman, \& Hope, 2014). In comparison to liars, truth tellers provide more verifiable details (Nahari \& Vrij, 2014), core details (Leal, Vrij, Deeb, \& Jupe, in press) and complications (Vrij, Leal, Jupe, \& Harvey, 2018), and present greater reconstructability and realism in their stories (Mac Giolla, Ask, Granhag \& Karlsson, 
in press). These differences are thought to stem from discrepancies in the nature of demand on memory for truth tellers and liars (Sporer \& Schwandt, 2006) and from different strategies used by truth tellers and liars (Vrij \& Granhag, 2012). Individuals providing an honest report can draw from existing memory structures, allowing them to provide longer, more elaborate responses. Meanwhile liars face the more cognitively challenging task of constructing, verbalising, and keeping track of their deceptive accounts (Dando, Bull, Ormerod, \& Sandham, 2013). There are also strategic benefits associated with shorter deceptive reports. For instance, providing less information means (i) there are fewer opportunities for liars to contradict themselves as evidence emerges through an interview (Hartwig, Granhag, Strömwall, \& Kronkvist, 2006), (ii) there are fewer leads for investigators to pursue which could reveal deception (Vrij, Leal, Mann, Vernham, \& Brankeart, 2015), (iii) there is leeway for verbal manoeuvring and adaptation as the interview progresses (Dando, Bull, Ormerod, \& Sandham, 2013), and (iv) it is easier to maintain consistency, as there are fewer details to remember to repeat in follow up interviews.

Consistency has been conceptualised in a number of ways relevant to the criminal justice system (for an overview, see Vredeveldt, van Koppen, \& Granhag, 2014). For instance, within-group consistency refers to the comparison of statements provided by multiple suspects (Granhag, Strömwall, \& Jonsson, 2003), whereas statement-evidence consistency is the evaluation of a suspect's statement in relation to any gathered evidence (Granhag \& Hartwig, 20151). Individual statements can be examined to establish the consistency within them (within-statement consistency; Leins, Fisher, Vrij, Leal, \& Mann, 2011). However, in investigations, suspects are often interrogated multiple times (Granhag \& Strömwall, 1999; Kassin et al., 2007; Miller \& Stiff, 1993) which allows for the comparison of multiple statements provided by a single suspect on a number of different occasions (between-statement consistency). When examining different statements from a single suspect, 
police have reported that they place a similar value on within-statement inconsistency and between-statement inconsistency (Deeb et al., 2018).

The 'repeat versus reconstruct' hypothesis (Granhag \& Strömwall, 1999) is probably the most prominent approach to examining the relationship of statement consistency and veracity in the lie detection literature. This hypothesis contends that, for liars, being consistent is an important aim in interviews. Over multiple interviews, reported details can be compared and classified into four categories in order to quantify consistency; repetition, omissions, reminiscences (sometimes referred to as commissions in deception research) and contradictions $^{1}$ (Fisher, Vrij, \& Leins, 2013).

In repeated interviews, it is hypothesised that liars think back to their earlier statements and try to repeat the same information to achieve their aim of being consistent. In contrast, truth tellers are thought to be less concerned with consistency between statements (Hartwig, Granhag, \& Strömwall, 2007) and more focused on remembering and reporting the encoding event. They are therefore less likely to focus on what was said in a previous interview, but more likely to think back to the originally encoded event and try to recall this event again, hereby generating reminiscent details and potentially omitting previously reported details (Granhag \& Strömwall, 1999; Granhag, Strömwall, \& Jonsson, 2003).

The occurrence of repetitions (information that is provided across all interviews or phases of an interview) increases apparent consistency, while the occurrence of omissions (information that is provided during a primary interview, but not mentioned in a subsequent interview) and reminiscences (information that is provided in a subsequent interview, but not provided in the primary interview) decrease consistency. Perceptions of consistency can mediate credibility judgments (Reinhard \& Sporer, 2008) and observers often utilise

\footnotetext{
${ }^{1}$ Contradictions rarely occur in experimental research (e.g. Granhag, Strömwall, \& Jonsson, 2003) and will not be discussed further.
} 
statement consistency as a cue to deception (de Keijser, Malsch, Kranendonk, \& de Gruijter, 2012; Roos af Hjelmsäter, Öhman, Granhag, \& Vrij, 2014). When individuals are tasked with assessing the veracity of consecutive statements given by one suspect, the most commonly reported cue sought is consistency (Granhag \& Strömwall, 2000, 2001), with $82 \%$ of police officers believing that truthful consecutive statements are more consistent than deceptive ones (Strömwall \& Granhag, 2003). Lay people express similar views about the relationship between consistency and deception (Krix, Sauerland, Lorei, \& Rispens, 2015; The Global Deception Research Team, 2006). This tendency has been referred to as the 'consistency heuristic' (Granhag \& Strömwall, 2000). However, research demonstrating the malleability and reconstructive nature of memory (Bartlett, 1920; Hemmer \& Steyvers, 2009; Michaelian, 2013) is incongruent with the consistency heuristic. With respect to statement consistency, memory research suggests that some types of inconsistency are a common feature of memory reports (Fisher, Brewer, \& Mitchell, 2009; Strange, Dysart, \& Loftus, 2015), with both reminiscences and omissions occurring without any detrimental effect on overall accuracy (Gilbert \& Fisher, 2006; Odinot, Memon, La Rooy, \& Millen, 2013). Consequently, in some situations, the consistency heuristic could be misleading, and cause a receiver to believe that such inconsistencies in an account might indicate that they are being deceived.

Protocols designed to actively elicit and magnify statement consistency as a useful cue to deception are still relatively understudied in lie detection research (Granhag, Mac Giolla, Sooniste, Strömwall, \& Liu-Jonsson, 2016; Vredeveldt, van Koppen, \& Granhag, 2014). However, research examining unanticipated questions (Granhag \& Mac Giolla, 2014) and changing interview modality, from verbal descriptions to drawing a sketch of a restaurant layout (Leins et al., 2011) or of a particular room (Leins, Fisher, \& Vrij, 2012) indicates that within-statement consistency of suspects can be magnified by introducing specific proactive interview protocols, resulting in diagnostic cues to deception. 
Practitioners often encourage applied researchers to examine the impact of using multiple techniques together, particularly when the techniques have already been tested individually. To address this, in the current experiment we introduced two different changes in interview format and examined their effects on liars' and truth tellers' accounts: introducing a request for a reverse order recall, similar to Vrij, Leal, Mann, and Fisher (2012) and switching the interviewer for a different interviewer, similar to Shaw et al. (2014).

Combining these two techniques, which have both independently shown promise with respect to increasing the amount of detail provided by truth tellers, could magnify the difference in truth tellers' and liars' performance to a level diagnostic of deception.

The reverse order recall strategy was initially developed to support memory retrieval as part of the Cognitive Interview (CI). Use of this technique may trigger recollection of additional details following a traditional chronological recall of an event (Fisher \& Geiselman, 1992). The reverse order recall instruction has been found to provide unsatisfactory results in some eyewitness interviews (Davis, McMahon, \& Greenwood, 2005; Memon, Wark, Bull, \& Koehnken, 1997), resulting in suggestions by some that it should be removed from the CI (Davis et al., 2005).

Vrij et al. (2008) interviewed 80 mock suspects about stealing $£ 10$ from a wallet. Half of the sample were innocent and were instructed to tell the truth about their actions, whereas the other half of the sample were guilty and were instructed to lie about their actions. Participants were asked to give their accounts in either chronological or reverse order. Liars who were asked to recall events in reverse order displayed more signs of cognitive load (e.g. spoke at a slower rate and provided fewer auditory details) than truth tellers, however the same effects were not found for those who recalled in chronological order. This suggests that when the reverse order recall technique is applied for liars, it results in additional cognitive load, as they try to work backwards through what they have previously reported (Vrij et al., 
2008). The change in recall order makes it more difficult for liars (cf. truthtellers) to monitor their consistency, as this unexpected method of questioning requires cognitive flexibility - a challenge for liars, who typically rehearse their deceptive accounts in a unidimensional manner (Leins et al., 2011). Consequently, increase in cognitive load as a result of reverse order recall should have a larger impact on liars than on truth tellers and thus should magnify the differences between them to a level that is diagnostic of deception.

In legal situations individuals may be interviewed a number of times by a range of individuals for example, police officers, social workers and lawyers. Research has suggested that using the same or different interviewers across repeated interviews has no effect on the accuracy of reported details (Odinot, Memon, La Rooy, \& Millen, 2013). However, previous research examining the effect of switching interviewers during an interview on cues to deceit found that a different interviewer (vs the same interviewer) in a second phase of an interview resulted in truth tellers providing more details, and liars providing fewer details (Shaw et al., 2014). The participants in Shaw et al.'s, (2014) research were interviewed by two interviewers about a mock security meeting that they had attended. In half of the interviews, new interviewers took over the interview half way through (the 'changed interviewer' condition). Otherwise, the same two interviewers conducted the entire interview ('same interviewer' condition). During the first half of the interviews, participants were required to provide their account in chronological order. In the second half of the interviews, participants were asked to provide a reverse order recall. It was found that differences in performance between truth tellers and liars were most prominent in the 'changed interviewer' condition, where truth tellers provided more detail and more repetitions in the second half of the interview than liars. This was not the case for the 'same interviewer' condition.

A new interviewer (vs the original interviewer) may motivate truth tellers to repeat more and omit fewer details because this new interviewer has not heard their story yet. In 
contrast, a switch in interviewers may make liars less motivated to be consistent (and therefore less motivated to repeat information) because it is more difficult for a new interviewer (cf. the original interviewer) to confirm consistency between two interviews.

In the current experiment, we asked liars and truth tellers to provide two accounts, across two phases of an interview, with a short break in between. All participants were asked to give a free recall of their actions in the first interview phase. After the break, either the same or a different interviewer asked the participants to report their account again, either as a free recall or using the reverse order recall instruction. As the two accounts were taken within the same interviewing session, we examined the within-statement consistency between the two accounts.

Most lie-detection studies involve assignment of participants to lie-telling conditions (Vrij, 2008). As these participants may lack the motivation and arousal of individuals who are lying of their own volition (Fisher \& Perez, 2007), we instead attempted to increase the ecological validity of our experimental paradigm by allowing participants to select whether they would tell the truth or lie (Wachi et al., 2017). Providing participants with the option to lie or tell the truth has been implemented in a variety of investigations into deceptive behaviour (Gneezy, 2005; Talwar \& Lee, 2008; Tyler, Feldmen \& Reichert, 2006), however, we recognise problematic features sometimes associated with this methodology. Whilst research has suggested that males and females lie with equal frequency (DePaulo, Kashy, Kirkendol, Wyer, \& Epstein, 1996), there is also evidence to suggest a gender difference in predisposition to lie, with research suggesting men are more likely to lie than women (Dreber \& Johannesson, 2008), as well as the inverse (Tyler et al., 2006). Furthermore, there is data to suggest younger people lie more than older individuals (DePaulo et al., 2006), with college students telling more lies per day than community members. For this reason, we carefully checked for the effect of gender and age across our truth telling and lie telling groups. 
Based on previous literature (Amado, Arce, \& Fariña, 2015; Gilbert \& Fisher, 2006; Granhag, Strömwall, \& Jonsson, 2003; Vrij, 2008; Vrij et al., 2014), we hypothesised that truth tellers would provide more details than liars in the first phase of their interviews (Hypothesis 1a) and more reminiscences than liars in the second phase of their interviews (Hypothesis 1b). As liars are more concerned about appearing consistent than truth tellers (Hartwig, Granhag, \& Strömwall, 2007), it was further predicted that liars would make fewer omissions (Hypothesis 2a) and more repetitions (Hypothesis 2b) in the second stage of their interviews than truth tellers. We also predicted that truth tellers would include more repetitions and fewer omissions when interviewed by a different interviewer in phase two of an interview than when interviewed by the same interviewer (Hypothesis 3a). In contrast, we hypothesised liars would include more repetitions and fewer omissions when interviewed by the same interviewer in phase two of an interview than when interviewed by a different interviewer (Hypothesis 3b). People's recollection is partially influenced by the retrieval cues that they use to search their memory, and the reverse order recall instruction disrupts the recollection of events from a schema (Gilbert \& Fisher, 2006). Therefore, we predicted that reverse order recall prompts would elicit more reminiscent details than chronological order interviews for truth tellers, but would not affect the amount of reminiscent detail reported by liars (Hypothesis 4), due to their concerns about consistency (Hartwig, Granhag \& Strömwall, 2007). Finally, we predicted that liars would include fewer repetitions and more omissions in reverse order recall attempts than in chronological order recall attempts, whereas this manipulation would not affect truth tellers' repetitions and omissions (Hypothesis 5).

\section{Method}

\section{Participants}


A total of 160 participants (49 male, 109 female, and 2 non-binary, with ages ranging from 18 years to 68 years, $M=24.09$ years, $S D=9.93$ years) were recruited from a university in the United Kingdom (126 participants were undergraduate students). Opportunity sampling was used for convenience. Participants received either extra course credit as part of a research participation scheme or $£ 5$ compensation if they were not eligible for course credit.

\section{Design}

We used a $2 \times 2 \times 2 \times 2$ mixed design, with Veracity (truth teller vs liar), Order of Recall (chronological order recall vs reverse order recall) and Interviewer (same second interviewer vs different second interviewer) as between subject factors, and Interview Phase (i.e. detail reported in Phase 1 vs detail reported in Phase 2) as a within-subject factor. Interviews were transcribed for analysis, and the number of details in each phase, and the repetitions, omissions and reminiscences found in Phase 2 were analysed as the dependent variables.

\section{Materials}

Stimulus materials. Truth tellers were asked to watch a BBC nature documentary clip. The documentary concerned caterpillar and butterfly survival, lasted 6 minutes and 32 seconds, and was rich in visual and narrative detail. A single page written synopsis of the documentary was also prepared in the style of a review (462 words).

Post interview questionnaires. Two questionnaires were presented to participants after they had finished both phases of their interview. One questionnaire focused on participants' demographic details (age, gender identification, profession), the other questionnaire asked about how well participants remembered what they had done (i.e. the tasks they had completed) and how they perceived the interview process. Nine questions included 7 point Likert scales $(1=$ not at all to $7=$ completely $)$ regarding how much they remembered of the tasks they completed, their motivation to be believed, and the extent to 
which they thought they were believed. Two open-ended questions asked participants to report on the strategies they adopted when providing their accounts. The questionnaires can be found at osf.io/kx $82 \mathrm{u} /$.

\section{Procedure}

Pre-interview instructions. After giving consent, participants were then presented with two envelopes; one labelled 'liar' and the other labelled 'truth teller'. They were informed that each envelope contained a set of keys to a room on the second floor of the building they were in, and a set of instructions regarding the tasks that they would be asked to complete, and then either later lie about in an interview (the 'liar' condition), or tell the truth about (the 'truth teller' condition). They were told that the instructions asked liars to steal a USB stick from an empty room, whereas truth tellers would be asked to watch a short nature documentary in an empty room. The researcher then left the room to give the participants time to decide which envelope (and, therefore, task) to select. They then placed the other envelope into a metal tin. Participants were informed that the researcher would not know which condition they chose until after they had completed the experiment. The majority of participants $(n=130)$ selected their preferred experimental condition in this way ${ }^{2}$.

Following the written instructions in the envelope truth tellers went alone to a research room and accessed a link to the nature documentary on a computer. Once the

${ }^{2}$ To correct for imbalances in the sample size between conditions, some participants signed up for the experiment having read an advert about solely the 'liar' condition $(n=30)$, and thus were not provided with the option to choose the 'truth teller' envelope. All truth tellers chose their condition $(n=87)$. Analyses to check for the presence of confounds differences between those who chose to lie compared to (i) those who chose to tell the truth and (ii) those who were given no choice but to lie are presented in the results section. 
documentary was finished, truth tellers then logged out of the computer, and returned to the room in which they had originally met the researcher.

In contrast, but also following written instructions, liars were directed to another room where they were asked to steal a classified USB stick. They were informed that the USB stick contained important computer coding regarding the privacy and safety of the University's intranet firewall, and they were asked to log on using stolen credentials to check the code before returning to the researcher. Liars were also provided with an outline of the nature documentary that they were informed truth tellers would watch. It was suggested that this synopsis might help them to claim as an alibi, during their interviews, that they were watching the documentary. Procedures where liars are provided with information they might use for an alibi (often a task completed by participants in a truth-telling condition) are common in deception research (e.g. Nahari \& Vrij, 2014; Strömwall, Granhag \& Jonsson, 2003). Once the liars had completed the tasks on the computer and logged off, they were also instructed to return to the room in which they had originally met the researcher.

When participants returned they were then taken through to the interview room.

The interview. Interviews were conducted by two male interviewers blind to the participants' veracity status. All participants were interviewed individually. All interviews were recorded using a digital recorder. A copy of the interview script is available at osf.io/dxfas/.

The first phase of each interview lasted on average 3 minutes and 33 seconds $(S D=1$ minute 41 seconds). Participants were not offered preparation time, and were told that they needed to convince the interviewer that they could not have stolen the USB device, as they had been watching the nature documentary. Firstly, the interviewer introduced himself, before informing the participants that some classified data had just been stolen. Participants were then asked to recall what they had been doing for the past 10 minutes. As expected, all 
participants claimed to have been watching a nature documentary. A second question asked participants to describe the documentary in chronological order, without guessing, and including as much detail as possible. Interviewers were instructed not to interrupt participants, or verbalise any encouragement, but could nod to indicate they were paying attention.

After participants had finished describing the documentary, they were thanked and asked to wait in the same room with the instruction that "someone will be with you shortly". Participants were left unattended for 3 minutes, before the second phase of each interview began. At this point, either the same person who conducted the first phase of the interview (same interviewer condition, $n=79$ ), or another interviewer (different interviewer condition, $n=81)$ entered the room. Participants were informed that there had been a problem with their previous statement, and that they needed to provide their report about the documentary again. Half of the participants received the same free recall instruction as in the first phase (i.e. chronological order, include as much detail as possible, don't guess, $n=81$ ), whereas the remainder of the interviewees were asked to recall the documentary in reverse order $(n=79)$. For the 'reverse order' condition, the interviewer explained what recalling the events in reverse order meant, and then participants were given an example of how one would describe making a cup of tea in reverse order. The interviewer asked the participants to confirm that they understood what was required, before instructing them to include as much detail as possible without guessing. The second phase of the interview lasted on average 3 minutes and 6 seconds $(S D=1$ minute 36 seconds $)$.

Post interview instructions. Once the interviews were complete, participants were asked to fill in the two post interview questionnaires, and to be completely honest in their responses. Following this they were fully debriefed, paid or awarded credits, and thanked for their time. 


\section{Coding of interview transcripts}

All audio recorded interviews were transcribed for analysis. Each interview transcript was first coded for number of details provided. (e.g. "the video had a white male narrating" would contain three details; the descriptors 'white' and 'male', and the action 'narrating'). Then, following Fisher, Vrij and Leins (2013), each detail provided in the second phase of the interview was coded for consistency. Repetitions were details reported in both phases of the interview, omissions were details reported in the first phase but not in the second phase of the interviews, reminiscences were details reported in the second phase but not in the first phase of the interviews, and contradictions were details reported in the first phase that were reported differently in the second phase. Due to very few contradictions being reported across conditions, this consistency category will not be considered further in the analyses. A subset of 40 interviews $(25 \%)$ were coded by a second researcher, who was blind to the experimental conditions. The inter-rater reliability between the coders was high for details in phase one of the interviews (intra-class correlation coefficient $[\mathrm{ICC}]=.83$ ) and details in phase two of the interviews (ICC $=.76$ ). Once again, these details were further classified for consistency, with satisfactory reliability being found between the two coders for repetitions $(\mathrm{ICC}=.73)$, reminiscences $(\mathrm{ICC}=.59)$ and omissions $(\mathrm{ICC}=.76)$.

\section{Results}

\section{Manipulation Checks}

Assignment to condition. A one-way MANOVA was conducted with condition allocation method for Liars (free choice vs forced choice) as the independent variable and total unique detail, detail provided at phase one, detail provided at phase two, omissions, reminiscences and repetitions as dependent variables to examine the effect of free choice or having been assigned a condition on liars' performance. The multivariate effect was not significant, $F(5,67)=1.92$, Wilks' $\Lambda=.88, p=.10, f=.38$. A series of manipulation checks 
were also conducted to examine whether the participants who chose to be a liar $(n=43)$ were significantly different to those who were assigned to the liar condition $(n=30)$ in motivation, confidence, age, gender or number of details provided. An independent measures $t$-test found that there was no significant difference between motivation levels of those who chose to lie compared to those who were assigned to the liar condition, $t(71)=.310, p=.76, d=.07$. Furthermore, there was no significant difference in the confidence levels, $t(71)=.37, p=.72$, $d=.09$. the age of free choice vs forced choice liars, $t(56.54)=1.78, p=.08, d=.39$, the amount of detail provided in the first phase of the interview, $t(71)=1.94, p=.15, d=.33$, or the second phase of the interview, $t(67.01)=1.96, p=.054, d=.44$. A chi-squared test using Fisher's exact test found that there were no significant differences in the gender divide of those who chose to be a liar compared to those who were assigned to the liar condition, $p=$ .42. The data for participants who chose to be liars and those who were assigned as liars were therefore collated in the subsequent analyses. An independent measures $t$-test found no significant difference in the age of those who chose to be truth tellers compared to liars, $t(156)=.66, p=.51, d=.11$, and a chi-squared test using Fisher's exact test found no significant difference in the gender representation within each experimental cell, $p=70$.

Motivation. A 2 (Veracity: truth teller vs liar) x 2 (Order of Recall: chronological order recall vs reverse order recall) x 2 (Interviewer: same second interviewer vs different second interviewer) ANOVA revealed no significant main or interaction effects on selfreported motivation scores, all $F$ 's $<3.08$, all $p$ 's $>.08$. The grand means reflected high levels of motivation $(M=5.87, S D=.94,95 \% \mathrm{CI}[5.72,6.02])$, with $74.5 \%$ of the sample reporting themselves as "very" (6) or "completely" (7) motivated.

Confidence in performance. A 2 (Veracity: truth teller vs liar) x 2 (Order of Recall: chronological order recall vs reverse order recall) x 2 (Interviewer: same second interviewer vs different second interviewer) ANOVA revealed that truth tellers reported higher 
confidence levels than liars (see Table 1). No other significant main or interaction effects were found for confidence in performance, all $F$ 's $<2.38$, all $p$ 's $>.13$.

Memory for stimulus. A 2 (Veracity: truth teller vs liar) x 2 (Order of Recall: chronological order recall vs reverse order recall) x 2 (Interviewer: same second interviewer vs different second interviewer) ANOVA revealed that truth tellers reported greater memory strength than liars (for truth tellers: self-reported memory strength for the video; for liars: self-reported memory strength for the synopsis of the documentary, see Table 1). There were no other significant main or interaction effects for memory strength for the stimulus, all $F$ 's $<$ 1.45 , all $p$ 's $>.23$.

Reported strategies. Overall, $38.4 \%$ of the sample reported using a strategy. Truth tellers were less likely to use a strategy, with $23 \%$ reporting using a strategy, compared to $56.9 \%$ of liars, a difference in proportions of $.34, p<.001$. Thematic examination of the reported strategies found the most common technique to relate to remembering/visualising the documentary (for truth tellers) or the summary of the documentary (for liars) in a lot of detail (reported by $54.1 \%$ of those who used a strategy), followed by considerations of nonverbal behaviour (reported by $31.14 \%$ of those who used a strategy). Other reported strategies included reporting truthful details (11.48\% of those who used a strategy), and not overthinking (3.28\% of those who used a strategy).

[Insert Table 1 about here]

\section{Veracity and Reporting}

A series of analyses were run to examine the difference in performance of truth tellers and liars on a number of factors (see Table 1). An independent measures t-test was conducted to compare the amount of detail provided in the first phase of the interview between truth tellers and liars. There was no significant difference in the amount of detail provided by veracity condition, $t(158)=1.24, p=.22, d=.20$, and consequently Hypothesis 1 a, that truth 
tellers would provide more details then liars in the first phase of their interviews, was not supported.

A 2 (Veracity: truth teller vs liar) x 2 (Order of Recall: chronological order recall vs reverse order recall) x 2 (Interviewer: same second interviewer vs different second interviewer) ANOVA revealed that truth tellers included more details in the second phase of their interviews than liars (see Table 1).

The number of unique details provided across both interview phases was calculated by combining the number of details reported in Phase 1 with the number of reminiscent details reported in Phase 2. No hypotheses were formed regarding reporting of unique detail, however exploratory analyses were run. A 2 (Veracity: truth teller vs liar) x 2 (Order of Recall: chronological order recall vs reverse order recall) x 2 (Interviewer: same second interviewer vs different second interviewer) ANOVA revealed that truth tellers reported more unique details in total than liars (see Table 1). No further effects were found, all F's $<2.84$, all $p ’ s>.09$.

Whilst there were no significant differences in the number of omissions or repetitions that truth tellers and liars provided, a 2 (Veracity: truth teller vs liar) x 2 (Order of Recall: chronological order recall vs reverse order recall) x 2 (Interviewer: same second interviewer vs different second interviewer) ANCOVA with the amount of detail provided in Phase 1 of the interview as a co-variate revealed that truth tellers included more reminiscence than liars (see Table 1). This supports Hypothesis $1 \mathrm{~b}$ that truth tellers, more so than liars, would provide reminiscences (additional detail) in the second phase of their interviews. Examinations of interactions and main effects for Order of Recall and Interviewer are presented below.

\section{Details Analyses}


We conducted a 2 (Veracity) x 2 (Order of Recall:) x 2 (Interviewer) x 2 (Interview Phase) mixed ANOVA with Interview Phase (i.e. detail reported in Phase 1 vs detail reported in Phase 2) as a within subject factor. Findings indicated a significant difference between the amount of detail reported in Phase $1(M=133.83, S D=65.52)$ and the amount of detail reported in Phase $2(M=91.82, S D=56.26), F(1,152)=74.38, p<.001, f=.70$. There was also an interaction effect of Order of Recall and Interview Phase, $F(1,152)=18.26, p<.001$, $f=.35$. To explore this interaction further, we broke it down to examine the effect on Phase 1 and Phase 2 of the interviews independently. Statistical significance of a simple main effect was accepted at a Bonferroni-adjusted alpha level of .025, in order to not capitalise on probabilities (Cramer et al., 2016). There was a statistically significant main effect of Order of Recall for detail reported in Phase 2, $F(1,158)=5.82, p=.02, f=.15$, but not in Phase $1, F(1,158)=3.74, p=.06, f=.19$. Mean detail reported in Phase 2 was higher for recall in chronological order than recall in reverse order, with a mean difference of $21.15,95 \%$ CI $[3.84,38.45], p=.02$. There was also a three way interaction identified between Interview Phase, Veracity and Interviewer, $F(1,152)=4.44, p=.04, f=.17$. To explore this interaction further, we examine Phase 1 and Phase 2 separately. Statistical significance of a simple twoway interaction was accepted at a Bonferroni-adjusted alpha level of .025. There were no statistically significant simple two-way interactions of Interviewer and Veracity for detail reported in Phase $1, F(1,156)=3.86, p=.051, f=.16$, or for detail reported in Phase $2, F(1$, $156)=.01, p=.94, f=.00$.

We examined the amount of detail provided in Phase 2 of the interview using a 2 (Veracity: truth teller vs liar) x 2 (Order of Recall: chronological order recall vs reverse order recall) x 2 (Interviewer: same second interviewer vs different second interviewer) ANOVA and found a further main effect for Order of Recall, $F(1,158)=6.01, p=.02, f=.20$. Those who reported their second statement in chronological order included more details overall ( $M$ 
$=102.26, S D=55.52,95 \% \mathrm{CI}[82.75,121.77])$ than those who reported it in reverse order $(M$ $=81.11, S D=55.31,95 \%$ CI $[61.43,100.79])$. No further main or interaction effects were found, all $F$ 's $<1.58$, all $p$ 's $>.21$.

\section{Consistency Analyses}

Consistency is related to the volume of information that is reported in the initial phase of an interview. For example, if more details are reported in phase one of the interview then there are subsequently more opportunities for repetitions or omissions and fewer opportunities for reminiscences in the second phase of the interview. To control for this, we analysed the effect of Veracity, Order of Recall and Interviewer upon repetitions, omissions and reminiscences with the amount of detail provided in phase one of the interview as a covariate. Contradictions did not occur frequently enough for inclusion in the analyses.

Omissions. A 2 (Veracity: truth teller vs liar) x 2 (Order of Recall: chronological order recall vs reverse order recall) x 2 (Interviewer: same second interviewer vs different second interviewer) ANCOVA with the amount of detail provided in Phase 1 of the interview as a co-variate revealed a main effect of Order of Recall on the number of omissions, $F(1$, $151)=24.02, p<.001, f=.40$. Those who reported in reverse order exhibited more omissions $(M=99.19, S D=55.33,95 \%$ CI $[87.79,112.81])$ than those who reported in chronological order $(M=63.20, S D=49.87,95 \%$ CI $[53.11,73.98])$. No other main effects were found, all $F^{\prime}$ s $<2.74$, all $p$ 's $>.10$, and consequently Hypothesis $2 \mathrm{a}$, that liars would prioritise consistency and therefore have fewer omissions than truth tellers, was not supported.

Repetitions. A 2 (Veracity: truth teller vs liar) x 2 (Order of Recall: chronological order recall vs reverse order recall) x 2 (Interviewer: same second interviewer vs different second interviewer) ANCOVA with the amount of detail provided in Phase 1 of the interview as a co-variate revealed a main effect for Order of Recall on the number of repetitions, $F(1$, 
$151)=23.44, p<.001, f=.40$. Individuals who reported in chronological order included more repetitions $(M=60.60, S D=33.68,95 \% \mathrm{CI}[53.28,68.14])$ than those who reported in reverse order $(M=44.68, S D=35.76,95 \%$ CI $[37.26,52.75])$. No further effects were found, all $F$ 's $<2.57$, all $p$ 's $>.11$, and consequently Hypothesis $2 \mathrm{~b}$, that liars would prioritise consistency and include more repetitions than truth tellers was not supported.

The Veracity X Interviewer interaction was not significant, $F(1,151)=2.57, p=.11$, $f=.00$, and therefore no support was found for Hypothesis 3 a that truth tellers would include more repetitions and fewer omissions when interviewed by a different interviewer in phase two compared to the same interviewer, or Hypothesis $3 \mathrm{~b}$ that liars would include more repetitions and fewer omissions when interviewed by the same interviewer compared to a different interviewer.

Reminiscent details. A 2 (Veracity: truth teller vs liar) x 2 (Order of Recall: chronological order recall vs reverse order recall) x 2 (Interviewer: same second interviewer vs different second interviewer) ANCOVA with the amount of detail provided in Phase 1 of the interview as a co-variate revealed a main effect of Interviewer on number of reminiscences, $F(1,151)=4.56, p=.03, f=.17$, which revealed that those interviewed by the same interviewer included more reminiscences $(M=45.15, S D=38.20,95 \%$ CI $[36.89$, 54.03]) than those interviewed by a different second interviewer $(M=32.53, S D=23.48$, $95 \%$ CI $[27.87,37.58])$. No further effects were found, all $F^{\prime}$ s $<2.36$, all $p$ 's $>.13$.

Hypothesis 4 predicted that reverse order recall would elicit more reminiscences than chronological order recall in truth tellers. To specifically test this hypothesis we compared the number of reminiscences provided in reverse order and chronological recalls for truth tellers only using a between subjects t-test. No significant difference was found, $t(85)=.65, p$ $=.52, d=.14$ with truth tellers including an average of $43.68(S D=36.04)$ reminiscent 
details in reverse order interviews, and an average of $48.40(S D=31.30)$ reminiscent details in chronological order.

Hypothesis 5 predicted that liars would make more omissions during reverse order recall than during chronological order recall. We examined this using a between subjects ttest and found that liars made significantly more omissions during reverse order recall $(M=$ 96.97, $S D=55.42,95 \%$ CI $[67.76,126.18])$ than during chronological order recall $(M=$ $57.95, S D=37.45,95 \%$ CI $[38.74,77.16]), t(71)=3.55, p=.001, d=.84$.

\section{Discussion}

Replicating previous findings in deception research, truth tellers provided more details than liars in the second phase of their interviews, as well as over both phases of the interview combined (Amado, Arce \& Farina, 2015; Vrij, 2008). However, fewer details were reported by both truth tellers and liars in the second phase of the interview when compared to the first phase, and there were no differences in the number of details provided by truth tellers or liars in the initial phase of the interviews. Our participants did not know they were going to be reinterviewed, and initially liars and truth tellers provided an equivalent amount of detail. When prompted to discuss the matter further, truth tellers were more likely than liars to expand their testimony to include new information, despite both groups providing less detail than in the previous phase of the interview. This expansion on testimony is often found in the 'encouraging interviewees to say more' deception literature (Vrij, Fisher, \& Blank, 2017). It is interesting to note the decrease in detail provided during the second phase of the interview by both truth tellers and liars, despite the increase in reminiscent details for truth tellers compared to liars, and no veracity-based differences for omissions or repetitions. We based our design on that of Leins et al., (2011) and Leins, Fisher, and Vrij (2012), who also examined within-statement consistency using two accounts taken from the same interviewing session. However, we instigated a shorter break between phases of the interview, and this 
could be considered a limitation of the design, resulting in a lack of motivation for participants to repeat the story in full again.

In addition, truth tellers included more reminiscent details during the second phase of their interviews than liars, but there were no significant differences between truth tellers and liars for the number of repetitions or omissions (see also Granhag, Strömwall \& Jonsson, 2003). This inclusion of reminiscent details suggests that truth tellers, more than liars, prioritised providing new information in Phase 2 of their interviews, instead of simply maintaining their original narrative. Reminiscences are commonly observed in memory research (Gilbert \& Fisher, 2006) and the current findings provide further support for the failure of liars to account for natural side effects of rudimentary memory systems (Harvey, Vrij, Leal, Hope, \& Mann, 2017). If we define statement consistency as the presence of repetitions and the absence of omissions and reminiscences, the findings suggest that liars were more consistent than truth tellers due to the relative absence of reminiscences in liars' accounts. This lack of consistency for truth tellers is generally found across the literature (see Vredeveldt, van Koppen \& Granhag, 2014 for an overview), although remains at odds with the popular belief that deception involves a lack of consistency.

In the current experiment, we introduced two manipulations during the interview process and examined their effects on liars' and truth tellers' statements: (i) introducing a prompt for reverse order recall, similar to Vrij, Leal, Mann, and Fisher (2012) and (ii) switching the interviewer, similar to Shaw et al. (2014). We were particularly interested in whether these manipulations would induce inconsistencies in liars. We found little evidence to support this notion. This may have been due to limitations with the liars' task, whereby liars were required to read a review-style synopsis of a Sir David Attenborough documentary, and to pretend that they had watched it. Due to the immense popularity of Sir David Attenborough's work in the United Kingdom (Smith, 2018), it is possible that liars were familiar with the 
style of Sir David Attenborough's work, and therefore able to perform at an overall similar level to the truth tellers.

When interviewed for the second phase of the interview, all individuals reporting in chronological order included more details and more repetitions than those reporting in reverse order. The number of omissions also increased for all individuals asked to recall in reverse order rather than chronological order, but the type of recall had no discernible effect on the number of reminiscences. The increase in omissions is most likely due to the increased cognitive load that results from reporting events in reverse order. The reverse order technique was designed as a memory enhancing task as part of the Cognitive Interview (Fisher \& Geiselman, 1992) designed to break script reliance and help trigger items without script rehearsal. Theoretically, this could have led to a greater number of reminiscences in truthful interviews, as honest interviewees were required to examine their memory utilising different retrieval processes to trigger further recollections (Fisher, Brewer \& Mitchell, 2009), though in this study we found no effect of Order of Recall on reminiscences. There was a significant effect of Order of Recall for liars, who exhibited significantly more omissions when reporting in reverse order. However, there was no significant difference in the number of omissions between truth tellers and liars when providing either chronological order or reverse order recalls, which suggests both groups found the tasks equally difficult. We speculate that this may be due to the brevity of the break between interview phases, whereby the information that participants had provided in Phase 1 of the interview was still fresh in their mind.

The number of reminiscent details reported increased for individuals interviewed by the same second interviewer, compared to those who were interviewed by a different interviewer in the second phase of their interview. One possible explanation for this finding is that the interviewees thought that the same interviewer had returned because $\mathrm{s} / \mathrm{he}$ was not satisfied with the amount of information s/he had initially gathered. This suggestion is speculative 
though, as there could be a variety of explanations for this increase in reminiscence, such as the context of talking to the same person again, or the familiarity of being interviewed by the same person. However, there were no significant differences in the number of repetitions provided, or omissions made by veracity condition as a result of changing interviewer, which may be due to the relatively short nature of the interviews. Establishing the effect of changing interviewers on statement consistency is important, considering how many people interview individuals being processed through the criminal justice system (e.g. investigators, lawyers, psychologists), and who operate with the belief that consistency is indicative of honesty (Bogaard \& Meijer, 2017). A better examination of the effect of this would be to compare changing or maintaining interviewers when interviewees are providing longer statements for personally experienced episodic events, as would likely be found in the criminal justice system.

The design of this study was somewhat similar to that of Shaw et al. (2014), although we were unable to replicate the effects they found when switching interviewer. Shaw et al. (2014) found that when the interviewers were changed partway through the interviews, truth tellers provided more detail in the second phase of the interviews than when presented with the same interviewer, and that their answers across both phases of the interviews included more repetitions than the answers provided by liars. In the current study, however, we only noted a difference in the number of reminiscences provided by interviewees due to changing interviewer. There are a number of methodological differences between the studies that might account for this discrepancy. First, Shaw et al. (2014) asked participants to fabricate information about an experience rather than providing them with information on which to base their alibi. Providing our participants with this alibi information prevented interviewees from crafting their own deception, which may be where the source of variance in performance arises. In addition, Shaw et al. (2014) used a coding system whereby participant 
statements were scored with respect to 18 key points and then subjectively rated for consistency. In comparison, our statements were objectively coded for every detail that the participant mentioned, which provided more opportunities for consistencies or inconsistencies to arise.

Most participants were provided with the opportunity to select their veracity condition, however there was a small subsection who were recruited in the knowledge they would be asked to lie. We propose that the latter group of participants were also afforded the option of participating as a liar, but this choice was presented at an earlier stage when they volunteered to participate knowing they would be required to lie. Research has shown there to be no difference in performance between those exhibiting forced and voluntary dishonesty (Geven, Selle, Ben-Shakhar, Kindt \& Verschuere, 2018; Nahari, Breska, Elber, Selle, \& Ben-Shakhar, 2016). Whilst the mixed nature of having free choice liars and forced liars may be considered a limitation, as there were no differences in the demographics, motivation or performance of participants in the current study, it was reasonable to combine these two groups for analysis. Furthermore, providing participants with the choice to be a liar or truth teller could be considered a limitation, as it may have introduced a systematic bias whereby the individuals who volunteered as liars were more practiced, and therefore possibly more skilled at deception. However, we argue that this choice is reflective of real life, where individuals make a decision as to whether they wish to lie about something. Therefore, those who may be uncomfortable with lying would be less likely to lie. When examining who chose to be a liar compared to those who chose to be a truth teller, we found no differences in background characteristics such as gender (consistent with DePaulo et al., [2006]) or age, nor did we find any difference in motivation levels across experimental cells, suggesting that those who chose to tell the truth, lie or were asked to lie were all equally motivated to succeed. We encourage further research into the impact of choice upon deceptive behaviour, and suggest 
future studies could consider examining the performance of both free choice and forced truth tellers and liars.

Considering the number of individuals who work within the criminal justice system, and operate under the belief that consistency is indicative of honesty (Strömwall \& Granhag, 2003; Bogaard \& Meijer, 2017), examining the statement consistency for truthful and deceptive suspects is important to help practitioners make informed veracity judgements. In the current study, we investigated the influence of recall order and a change in interviewer on the within-statement consistency of both truth tellers and liars. This has important implications for those involved in the criminal justice system, where suspects may be interviewed multiple times by different people, and be subject to a variety of interviewing techniques throughout their interviews. No effects were found for changing the interviewer and changing the recall order on repetitions and omissions. It seems therefore that the combination of these interviewing techniques is not necessarily beneficial for enhanced deception detection.

Despite the popular belief that inconsistency is a cue to deception, we also found little support for the notion that consistency (or lack of consistency) offers diagnostic cues to deception. If anything, due to the natural occurrence of reminiscences in our truth tellers' statements, as is commonly found in memory research (Gilbert \& Fisher, 2006), our findings suggest that liars are more consistent than truth tellers, and that the consistency heuristic is an inconsistent and impractical cue to deception. 


\section{References}

Aamodt, M. G., \& Custer, H. (2006). Who can best catch a liar? A meta-analysis of individual differences in detecting deception. The Forensic Examiner, 15, 7-11. Amado, B.G., Arce, R., \& Fariña, F. (2015). Undeutsch hypothesis and Criteria Based Content Analysis: A meta-analytic review. The European Journal of Psychology Applied to Legal Context, 7, 3-12. DOI: 10.1016/j.ejpal.2014.11.002.

Bartlett, F. C. (1920). Some experiments on the reproduction of folk-stories. Folklore, 31, 30-47. DOI: 10.1080/0015587X.1920.9719123

Bogaard, G., \& Meijer, E. H. (2017). Self-Reported Beliefs About Verbal Cues Correlate with Deception-Detection Performance. Applied Cognitive Psychology. DOI: $10.1002 /$ acp. 3378

Bond, C. F., \& DePaulo, B. M. (2006). Accuracy of deception judgements. Personality and Social Psychology Review, 10, 214-234. DOI: 10.1016/j.jarmac.2012.04.010.

Brock, P., Fisher, R. P., \& Cutler, B. L. (1999). Examining the cognitive interview in a double-test paradigm. Psychology, Crime \& Law, 5, 29-45. DOI: $10.1080 / 10683169908414992$

Cohen, J. (1992). A power primer. Psychological Bulletin, 112, 155-159. DOI: $10.1037 / 0033-2909.112 .1 .155$

Cramer, A. O., van Ravenzwaaij, D., Matzke, D., Steingroever, H., Wetzels, R., Grasman, R. P., Waldorp, L. J., \& Wagenmakers, E. J. (2016). Hidden multiplicity in exploratory multiway ANOVA: Prevalence and remedies. Psychonomic bulletin \& review, 23, 640-647. DOI: 10.3758/s13423-015-0913-5

Dando, C. J., Bull, R., Ormerod, T. C., \& Sandham, A. L. (2013). Helping to sort the liars from the truth-tellers: The gradual revelation of information during investigative interviews. Legal and Criminological Psychology, 20, 114-128. DOI: 
10.1111/lcrp.12016.

Davis, M. R., McMahon, M., \& Greenwood, K. M. (2005). The efficacy of mnemonic components of the Cognitive Interview: Towards a shortened variant for time-critical investigations. Applied Cognitive Psychology, 19, 75-93. DOI: 10.1002/acp.1048.

Deeb, H., Vrij, A., Hope, L., Mann, S., Granhag, P. A., \& Strömwall, L. A. (2018). Police officers' perceptions of statement inconsistency. Criminal Justice and Behavior, 1-22. DOI: $10.1177 / 0093854818758808$

de Keijser, J., Malsch, M., Kranendonk, R., \& de Gruijter, M. (2012). Written records of police interrogation: differential registration as determinant of statement credibility and interrogation quality. Psychology, Crime \& Law, 18, 613-629, DOI: 10.1080/1068316X.2010.526119

DePaulo, B. M., Kashy, D. A., Kirkendol, S. E., Wyer, M. M., \& Epstein, J. A. (1996). Lying in everyday life. Journal of personality and social psychology, 70, 979-995. DOI: $10.1037 / 0022-3514.70 .5 .979$

Dreber, A., \& Johannesson, M. (2008). Gender differences in deception. Economics Letters, 99, 197-199. DOI: 10.1016/j.econlet.2007.06.027

Faul, F., Erdfelder, E., Lang, A. G., \& Buchner, A. (2007). G* Power 3: A flexible statistical power analysis program for the social, behavioral, and biomedical sciences. Behavior research methods, 39, 175-191. DOI: 10.3758/BF03193146

Fisher, R. P., Brewer, N., \& Mitchell, G. (2009). The relation between consistency and accuracy of eyewitness testimony: Legal versus cognitive explanations. In T. Williamson, R. Bull, \& T. Valentine (Eds.), Handbook of psychology of investigative interviewing: Current developments and future directions (pp. 121-136). Chichester: Wiley-Blackwell 
Fisher, R. P., \& Geiselman, R. E. (1992). Memory-enhancing techniques for investigative interviewing: The cognitive interview. Springfield, IL: Charles C. Thomas.

Fisher, R. P., \& Perez, V. (2007). Memory-enhancing techniques for interviewing crime suspects. In S. Å. Christianson (Ed.), Offenders' memories of violent crimes (pp. 329 -354). Chichester, UK: Wiley.

Fisher, R. P., Vrij, A., \& Leins, D. A. (2013). Inconsistency as a predictor of memory inaccuracy and lying. Applied issues in investigative interviewing, eyewitness memory, and credibility assessment. New York, NY: Springer.

Granhag, P. A., \& Hartwig, M. (2015). The strategic use of evidence technique: A conceptual overview. In P. A. Granhag, A. Vrij, \& B. Verschuere (Eds.), Deception Detection: Current challenges and cognitive approaches (pp. 231-251). Chichester: John Wiley

Granhag, P. A., \& Mac Giolla, E. (2014). Preventing future crimes. European Psychologist, 19. 195-206 DOI: 10.1027/1016-9040/a000202.

Granhag, P. A., Mac Giolla, E., Sooniste, T., Strömwall, L., \& Liu-Jonsson, M. (2016). Discriminating between statements of true and false intent: The impact of repeated interviews and strategic questioning. Journal of Applied Security Research, 11, 117. DOI: $10.1080 / 19361610.2016 .1104230$.

Granhag, P. A., \& Strömwall, L. A. (1999) Repeated interrogations-stretching the deception detection paradigm. Expert Evidence, 7, 163-174. DOI: 10.1023/A:1008993326434.

Granhag, P. A., \& Strömwall, L. A. (2000). In C. M. Breur, M. M. Kommer, J. F. Nijboer, \& J. M. Reintjes (Eds.), New trends in criminal investigation and evidence, Vol. 2 (pp. 309-321). Antwerp, Belgium: Intersentia. 
Granhag, P. A., \& Strömwall, L. A. (2001). Deception detection: Interrogators' and observers' decoding of consecutive statements. The Journal of Psychology, 135, 603-620. DOI: 10.1080/00223980109603723.

Granhag, P. A., Strömwall, L. A., \& Jonsson, A. C. (2003). Partners in crime: How liars in collusion betray themselves. Journal of Applied Social Psychology, 33, 848-868. DOI: 10.1111/j.1559-1816.2003.tb01928.x.

Geven, L. M., Selle, N. K., Ben-Shakhar, G., Kindt, M., \& Verschuere, B. (2018). Selfinitiated versus instructed cheating in the physiological Concealed Information Test. Biological psychology, 138, 146-155. DOI: 10.1016/j.biopsycho.2018.09.005.

Gilbert, J. A., \& Fisher, R. P. (2006). The effects of varied retrieval cues on reminiscence in eyewitness memory. Applied Cognitive Psychology, 20, 723-739. DOI: 10.1002/acp.1232.

Gneezy, U. (2005). Deception: The role of consequences. American Economic Review, 95, 384-394. DOI: $10.1257 / 0002828053828662$

Hartwig, M., Granhag, P. A., \& Strömwall, L. A. (2007). Guilty and innocent suspects' strategies during police interrogations. Psychology, Crime \& Law, 13, 213-227. DOI: $10.1080 / 10683160600750264$

Hartwig, M., Granhag, P. A., Strömwall, L. A., \& Kronkvist, O. (2006). Strategic use of evidence during police interviews: When training to detect deception works. Law and human behavior, 30, 603-619. DOI: 10.1007/s10979-006-9053-9

Hartwig, M., Granhag, P. A., Strömwall, L., Wolf, A. G., Vrij, A., \& Hjelmsäter, E. R. A. (2011). Detecting deception in suspects: Verbal cues as a function of interview strategy. Psychology, Crime \& Law, 17, 643-656. DOI: $10.1080 / 10683160903446982$. 
Harvey, A. C., Vrij, A., Leal, S., Hope, L., \& Mann, S. (2017). Deception and Decay: Verbal Lie Detection as a Function of Delay and Encoding Quality. Journal of Applied Research in Memory and Cognition, 6, 306-318. DOI:

10.1016/j.jarmac.2017.04.002

Hauch, V., Sporer, S. L., Michael, S. W., \& Meissner, C. A. (2016). Does training improve the detection of deception? A meta-analysis. Communication Research, 43, 283343. DOI: $10.1177 / 0093650214534974$.

Hemmer, P., \& Steyvers, M. (2009). A Bayesian account of reconstructive memory. Topics in Cognitive Science, 1, 189-202. DOI: 10.1111/j.1756-8765.2008.01010.x.

Hope, L., Gabbert, F., Fisher, R. P., \& Jamieson, K. (2014). Protecting and enhancing eyewitness memory: The impact of an initial recall attempt on performance in an investigative interview. Applied Cognitive Psychology, 28, 304-313. DOI: $10.1002 /$ acp. 2984

Kassin, S. M., Leo, R. A., Meissner, C. A., Richman, K. D., Colwell, L. H., Leach, A. M., \& La Fon, D. (2007). Police interviewing and interrogation: A self-report survey of police practices and beliefs. Law and human behavior, 31, 381-400. DOI: 10.1007/s10979-006-9073-5.

Krix, A. C., Sauerland, M., Lorei, C., \& Rispens, I. (2015). Consistency across repeated eyewitness interviews: Contrasting police detectives' beliefs with actual eyewitness performance. PloS one, 10, e0118641. DOI: 10.1371/journal.pone.0118641.

Leal, S., Vrij, A., Deeb, H., \& Jupe, L. (in press). Using the model statement to elicit verbal differences between truth tellers and liars: the benefit of examining core and peripheral details. Journal of Applied Research in Memory and Cognition. DOI: 10.1016/j.jarmac.2018.07.001.

Leins, D. A., Fisher, R. P., \& Vrij, A. (2012). Drawing on liars' lack of cognitive flexibility: 
Detecting deception through varying report modes. Applied Cognitive Psychology, 26, 601-607. DOI: 10.1002/acp.2837.

Leins, D., Fisher, R. P., Vrij, A., Leal, S., \& Mann, S. (2011). Using sketch drawing to induce inconsistency in liars. Legal and Criminological Psychology, 16, 253-265. DOI: $10.1348 / 135532510 \times 501775$.

Mac Giolla, E., Ask, K., Granhag, P. A., \& Karlsson, A. (in press). Can Reality Monitoring Criteria Distinguish Between True and False Intentions?. Journal of Applied Research in Memory and Cognition. DOI: 10.1016/j.jarmac.2018.08.002.

Memon, A., Wark, L., Bull, R., \& Koehnken, G. (1997). Isolating the effects of the cognitive interview techniques. British Journal of Psychology, 88, 179-197. DOI: 10.1111/j.2044-8295.1997.tb02629.x.

Michaelian, K. (2013). The information effect: Constructive memory, testimony, and epistemic luck. Synthese, 190, 2429-2456. DOI 10.1007/s11229-011-9992-7.

Miller, G. R., \& Stiff, J. B. (1993). Deceptive communication. Newbury Park, CA: Sage Publications, Inc.

Nahari, G., \& Vrij, A. (2014). Can I borrow your alibi? The applicability of the verifiability approach to the case of an alibi witness. Journal of Applied Research in Memory and Cognition, 3, 89-94. DOI: 10.1016/j.jarmac.2014.04.005.

Nahari, T., Breska, A., Elber, L., Klein Selle, N., \& Ben-Shakhar, G. (2017). The external validity of the Concealed Information Test: The effect of choosing to commit a mock crime. Applied Cognitive Psychology, 31, 81-90. DOI: 10.1002/acp.3304.

Odinot, G., Memon, A., La Rooy, D., \& Millen, A. (2013). Are two interviews better than one? Eyewitness memory across repeated cognitive interviews. PLoS One, 8 , e76305. DOI: 10.1371/journal.pone.0076305.

Reinhard, M. A., \& Sporer, S. L. (2008). Verbal and nonverbal behaviour as a basis for 
credibility attribution: The impact of task involvement and cognitive capacity. Journal of Experimental Social Psychology, 44, 477-488. DOI: 10.1016/j.jesp.2007.07.012.

Roos af Hjelmsäter, E., Öhman, L., Granhag, P. A. and Vrij, A. (2014), 'Mapping' deception in adolescents: Eliciting cues to deceit through an unanticipated spatial drawing task. Legal and Criminological Psychology, 19, 179-188. DOI: 10.1111/j.20448333.2012.02068.x.

Shaw, D. J., Vrij, A., Leal, S., Mann, S., Hillman, J., Granhag, P. A., \& Fisher, R. P. (2014). 'We'll take it from here': the effect of changing interviewers in information gathering interviews. Applied Cognitive Psychology, 28, 908-916. DOI: 10.1002/acp.3072.

Smith, M. (2018). David Attenborough is the most popular person in Britain (YouGov Ratings). Retrieved from https://yougov.co.uk/topics/entertainment/articlesreports/2018/11/07/david-attenborough-most-popular-person-britain.

Sporer, S. L., \& Schwandt, B. (2006). Paraverbal indicators of deception: A meta-analytic synthesis. Applied Cognitive Psychology, 20, 421-446. DOI: 10.1002/acp.1190.

Strange, D., Dysart, J., \& Loftus, E. F. (2015). Why errors in alibis are not necessarily evidence of guilt. Zeitschrift für Psychologie. 222, 82-89. DOI: 10.1027/2151$2604 / \mathrm{a} 000169$.

Strömwall, L., \& Granhag, P. A. (2003). How to detect deception? Arresting the beliefs of police officers, prosecutors and judges. Psychology, Crime and Law, 9, 19-36. DOI: $10.1080 / 10683160308138$.

Talwar, V., \& Lee, K. (2008). Social and cognitive correlates of children's lying behavior. Child development, 79, 866-881. DOI: 10.1111/j.1467-8624.2008.01164.x ten Brinke, L., Vohs, K. D., \& Carney, D. R. (2016). Can ordinary people detect deception after all?. Trends in cognitive sciences, 20, 579-588. DOI: 
10.1016/j.tics.2016.05.012

The British Psychological Society (2014). Code of Human Research Ethics. Leicester, UK: The British Psychological Society.

The Global Deception Research Team. (2006). A world of lies. Journal of cross-cultural psychology, 37, 60-74. DOI: 10.1177/0022022105282295.

Tyler, J. M., Feldman, R. S., \& Reichert, A. (2006). The price of deceptive behavior: Disliking and lying to people who lie to us. Journal of Experimental Social Psychology, 42, 69-77. DOI: 10.1016/j.jesp.2005.02.003

Vredeveldt, A., van Koppen, P. J., \& Granhag, P. A. (2014). The inconsistent suspect: A systematic review of different types of consistency in truth tellers and liars. In Investigative Interviewing (pp. 183-207). New York: Springer.

Vrij, A. (2008). Detecting lies and deceit: Pitfalls and opportunities (2nd ed.). Chichester: Wiley.

Vrij, A., Fisher, R. P., \& Blank, H. (2017). A cognitive approach to lie detection: A metaanalysis. Legal and Criminological Psychology, 22, 1-21. DOI: 10.1111/lcrp.12088/full.

Vrij, A., \& Granhag, P. A. (2012a). Eliciting cues to deception and truth: What matters are the questions asked. Journal of Applied Research in Memory and Cognition, 1, 110117. DOI: $10.1016 /$ j.jarmac.2012.02.004

Vrij, A., Granhag, P. A., Mann, S., \& Leal, S. (2011). Outsmarting the liars: Toward a cognitive lie detection approach. Current Directions in Psychological Science, 20, 28-32. DOI: 10.1177/0963721410391245.

Vrij, A., Leal, S., Jupe, L., \& Harvey, A. (2018). Within-subjects verbal lie detection measures: A comparison between total detail and proportion of complications. Legal and Criminological Psychology, 23, 265-279. DOI: 10.1111/lcrp.12126 
Vrij, A., Leal, S., Mann, S., \& Fisher, R. (2012). Imposing cognitive load to elicit cues to deceit: Inducing the reverse order technique naturally. Psychology, Crime, \& Law, 18, 579-594. DOI: 10.1080/1068316X2010.515987

Vrij, A., Leal, S., Mann, S., Vernham, Z., \& Brankeart, F. (2015). Translating theory into practice: Evaluating a cognitive lie detection training workshop. Journal of Applied Research in Memory and Cognition, 4, 110-120. DOI:

10.1016/j.jarmac.2015.02.002.

Vrij, A., Mann, S. A., Fisher, R. P., Leal, S., Milne, R., \& Bull, R. (2008). Increasing cognitive load to facilitate lie detection: The benefit of recalling an event in reverse order. Law and human behavior, 32, 253-265. DOI: 10.1007/s10979-007-9103-y.

Vrij, A., Mann, S., Jundi, S., Hillman, J., \& Hope, L. (2014). Detection of concealment in an information-gathering interview. Applied Cognitive Psychology, 28, 860-866. DOI: 10.1002/acp.3051.

Wachi, T., Kuraishi, H., Watanabe, K., Otsuka, Y., Yokota, K., \& Lamb, M. E. (2017). Police officers' ability to detect lies within a deception paradigm. Psychology, Public Policy, and Law, 23, 301-311. DOI: 10.1037/law0000124 


\section{Table 1.}

The difference in performance of truth tellers and liars.

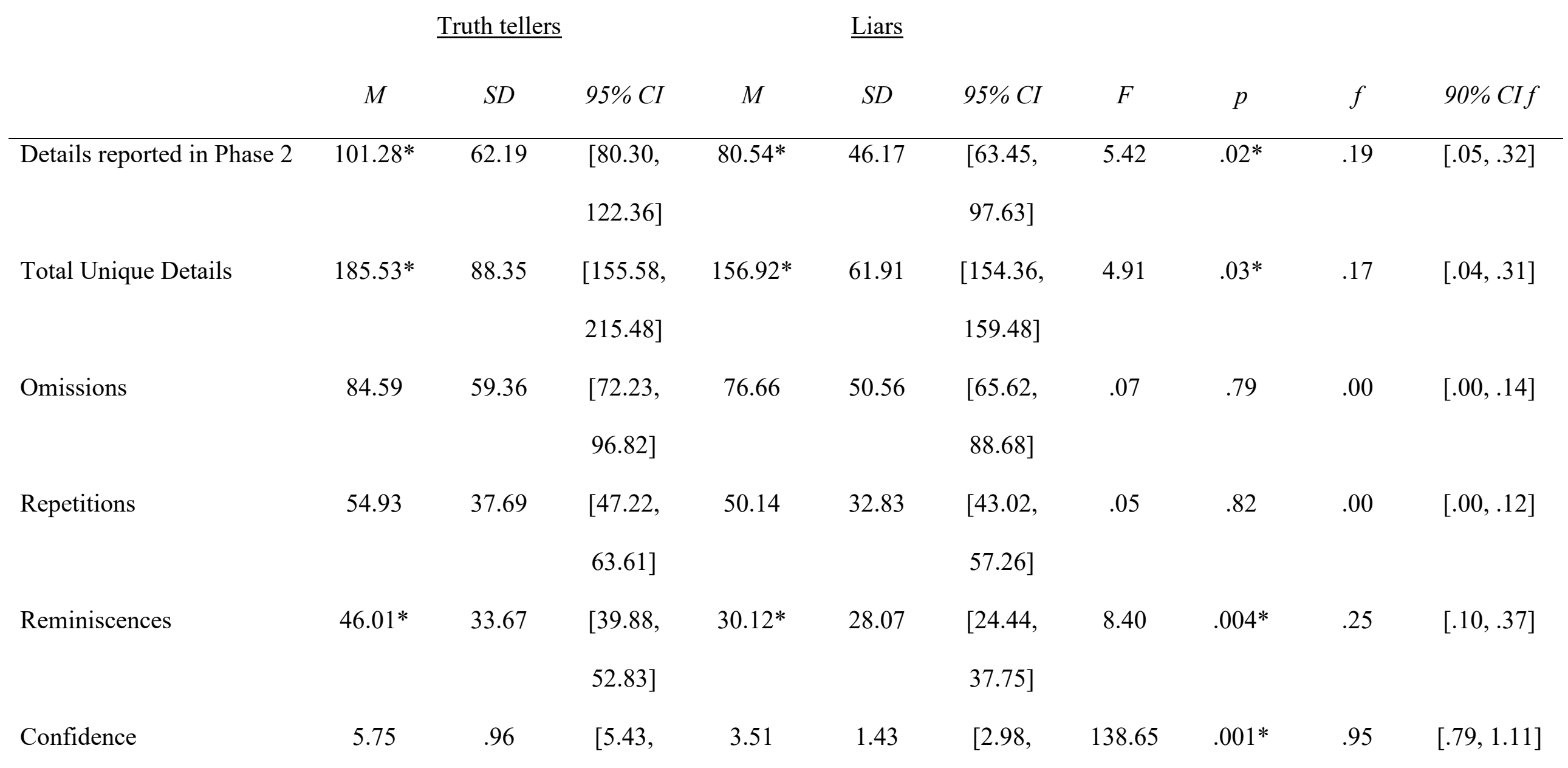


$6.08]$

Memory

5.95

.65

$[5.72$,

5.52

1.16

$6.18]$

$5.95]$

$4.04]$

Notes: Statistically significant differences are highlighted with an asterix. 